Monografias Ambientais

(e-ISSN: 2236-1308)

REMOANFSM

\title{
PERCEPÇÕES DE ALUNOS SURDOS EM TRILHA ECOLÓGICA COM O USO DOS DIFERENTES SENTIDOS: UMA ABORDAGEM DA EDUCAÇÃO AMBIENTAL
}

\author{
Paula Boos Höher, Paulo Edelvar Corrêa Peres
}

\section{RESUMO}

A percepção que temos perante o ambiente pode facilitar a compreensão do mundo em suas diversas formas. Esta percepção ocorre por meio dos nossos cinco sentidos, os quais ajudam a despertar o interesse pelo ambiente que nos cerca e a admiração pelo mundo natural. Independente do motivo, quando nos é privado algum desses sentidos, passamos naturalmente a aumentar a capacidade de percepção nos outros quatro. Atualmente entende-se a surdez como diferença, caracterizando os sujeitos surdos como pertencentes a grupos linguísticos minoritários, constituídos social, política e culturalmente diferentes. Com isto, justifica-se este trabalho pela extrema importância de proporcionar aos sujeitos surdos atividades práticas que os levem a utilizar seus diferentes sentidos, com o objetivo de melhor perceberem o ambiente natural. Para o desenvolvimento desta atividade, foi utilizada a trilha do Lago, situada dentro do campus da Universidade do Vale do Rio dos Sinos (UNISINOS), dividida em estações. Participaram da trilha um grupo de alunos surdos. Ao final da atividade os alunos registraram suas percepções da trilha em desenhos e respondendo a um questionário. Pode-se observar que o sujeito surdo utiliza todos os seus sentidos para perceber o ambiente de forma integral. Pela falta da audição, são mais sensíveis ao visual, conseguindo estabelecer relações perfeitas com o meio ambiente. A partir dos resultados obtidos, percebemos que os desenhos dos alunos apresentam elementos significativos, bem como suas considerações, evidenciando uma percepção plena do ambiente.

Palavras-chave: Percepção. Trilha. Surdos. Meio ambiente. Educação Ambiental.

\section{ABSTRACT}

The perception we have to the environment can facilitate the understanding of the world in its various forms. This perception is through our five senses, which help to arouse interest in the environment around us and admiration for the natural world. Whatever the reason, when we are deprived of any sense, we naturally increase the capacity of perception in the other four. Currently means deafness as a difference, featuring deaf subjects as belonging to minority language groups, consisting of social, political and culturally different. With this, this work is justified by the extreme importance of providing deaf subjects practical activities that lead them to use their different senses, in order to better understand the natural environment. For the development of this activity was used the "Path the Lake", located on the Campus of the University UNISINOS, divided into stations. A group of deaf students went through this path. At the end of the activity the students recorded their perceptions of the path in drawings and answering a questionnaire. It can be observed that the deaf subject using all their senses to perceive the environment holistically. For lack of hearing, are more sensitive to the visual, it established relations with the perfect environment. From the results obtained, we can see that the designs of students present significant elements, as well as their concerns, showing a full understanding of the environment.

Keywords: Perception. Path. Deaf. Environment. Environmental Education. 


\section{INTRODUÇÃO}

A percepção que temos perante o ambiente pode facilitar a compreensão do mundo em suas diversas formas. Esta percepção ocorre por meio dos nossos cinco sentidos: visão, olfato, tato, paladar e audição, os quais ajudam a despertar o interesse pelo ambiente que nos cerca e a admiração pelo mundo natural. Independente do motivo, quando nos é privado algum desses sentidos, passamos naturalmente a aumentar a capacidade de percepção nos outros quatro.

Segundo Tuan (1980), o tato é a experiência direta do mundo. Os olhos exploram o campo visual, porém as sensações somente serão experienciadas através do tato. De acordo com o mesmo autor, as atividades de percepção são aquelas que propiciam vivências significativas a partir dos órgãos dos sentidos. Para o autor:

A percepção é uma atividade, um estender-se para o mundo. Os órgãos dos sentidos são pouco eficazes quando não são ativamente usados. Nosso sentido tátil é muito delicado, mas para diferenciar a textura ou dureza das superfícies não é suficiente colocar um dedo sobre elas; o dedo tem que se movimentar sobre elas. É possível ter olhos e não ver; ouvidos e não ouvir (TUAN, 1980, p. 14).

A percepção ambiental pode ser entendida como o pressuposto para formação do conhecimento e da conscientização ambiental. Perceber o ambiente no qual está inserido é uma das formas de vivenciar os conteúdos curriculares, os quais muitas vezes, encontram-se obscuros e mascarados nas práticas pedagógicas convencionais.

A formação de um cidadão crítico exige sua inserção numa sociedade em que o conhecimento científico e tecnológico é cada vez mais valorizado. Além disso, a aproximação deste sujeito com as questões socioambientais permite que este esteja rodeado de conceitos e práticas multidisciplinares, que irão de encontro com sua realidade. Neste contexto, de acordo com os Parâmetros Curriculares Nacionais (BRASIL, 1998), o papel das Ciências Naturais e Biologia é o de colaborar para a compreensão do mundo e suas transformações, situando o homem como indivíduo participativo e parte integrante do Universo. A questão ambiental vem sendo considerada cada vez mais urgente e importante para a sociedade, pois o futuro da humanidade depende da relação estabelecida entre a natureza e o uso pelo homem dos recursos naturais disponíveis. Por estas razões, vê-se a importância de se incluir a Educação Ambiental nas práticas escolares.

Saviani (2000, p. 41) afirma que o caminho do conhecimento:

É perguntar dentro da cotidianidade do aluno e na sua cultura; mais que ensinar e aprender um conhecimento, é preciso concretizá-lo no cotidiano, questionando, respondendo, avaliando, num trabalho desenvolvido por grupos e indivíduos que constroem o seu mundo e o fazem por si mesmos.

Leff (2003) fala da aprendizagem ambiental como um saber pedagógico e interpretativo nos processos de elaboração de conhecimentos comuns, sobre a sustentabilidade ecológica, social, cultural e econômica do planeta. Como saber prático, deve criar estratégias e ações de ensino-aprendizagem dentro e fora da escola, contextualizando as relações de aprendizagem com os saberes comuns da realidade dos educandos.

Pensando na educação de surdos, por muito tempo, estes eram sinônimos de anormalidade, para a qual deveriam ser pensadas práticas de normalização, sendo a avaliação o instrumento para isso. Discutindo o conceito de surdez, em um de seus textos, Skliar (1998, p. 13) 
a define como "uma diferença construída histórica e socialmente, efeito de conflitos sociais, ancorada em práticas de significação e representações compartilhadas entre os surdos".

Entendendo a surdez como diferença, Lopes (2004) afirma que encaram-se sujeitos surdos como pertencentes a grupos lingüísticos minoritários, constituídos social, política e culturalmente diferentes. Porém a maioria das práticas de metodologias para surdos tem sido realizadas a partir dos mesmos referenciais utilizados para ouvintes, ignorando essas diferenças. Como consequência vem o quadro de fracasso escolar. Com isto, torna-se necessário repensar as metodologias de ensino para surdos, vinculando estas a vivências práticas e motivadoras, dando ênfase a elementos visuais, para que se torne prazerosa a aprendizagem.

Wrigley (1996) tenta descrever o mundo dos surdos sendo como um país cuja história é rescrita de gerações a gerações. As Línguas de Sinais são como conhecimento social da surdez, vão evoluindo e sendo modificadas ao longo do tempo. Partindo disso, a surdez vista como diferença se retrata a pessoas com necessidades especiais, diferenciadas, levando em consideração suas potencialidades, cultura e língua. Libras (Língua Brasileira de Sinais) é a língua usada pela comunidade surda no Brasil. É uma língua que expressa níveis linguísticos em diferentes graus, assim como as demais línguas; apresenta uma gramática com uma estrutura própria, usada por um grupo social específico (QUADROS, 2004; QUADROS; KARNOPP, 2004). Sacks (1998) complementa que num nível neurológico, a língua de sinais é uma língua e é tratada como tal pelo cérebro, apesar de ser visual em vez de auditiva e espacial em vez de sequencialmente organizada. $E$, sendo uma língua, ela é processada pelo hemisfério cerebral esquerdo, o qual é biologicamente e especializado exatamente para essa função.

A partir dessas constatações podemos ter uma melhor compreensão e percepção da abordagem sobre os cidadãos surdos e suas relações. Hoje, estamos convictos de que as representações da surdez devem ser encaradas e estudadas como diferença. Tal envolve a língua de sinais, comunidade surda, identidades e cultura surda. Todo este processo social perpassa pela cultura que nada mais é do que um comportamento cultivado ou adquirido por convivências sociais.

Sendo assim, justifica-se este trabalho pela extrema importância de proporcionar aos sujeitos surdos atividades práticas que os levem a utilizar seus diferentes sentidos, com o objetivo de melhor perceberem o ambiente e suas relações. Com isto as atividades envolvendo trilhas tornam-se investigativas, levando os participantes a fazerem interpretações e avaliações do ambiente. Os autores Saul, Leal e Fensterseifer (2002, p. 107) afirmam que:

As trilhas são um recurso valioso no reconhecimento e interpretação do ambiente. Sendo previamente delimitadas, em geral aproveitando caminhos já existentes, permitem aos mais diferentes públicos a observação e a vivência de um conjunto de aspectos, naturais ou não, do seu entorno.

As atividades envolvendo trilhas interpretativas têm o objetivo de capturar e traduzir informações do Meio Ambiente. Contudo, não lidam apenas com informações, mas com significados e conhecimentos, exercitando valores, criando perspectivas, fomentando a participação da comunidade e trabalhando a percepção, a curiosidade e a criatividade humana. As trilhas, como meio de interpretação ambiental, visam não somente a transmissão de conhecimentos, mas também possibilitam práticas que revelam os significados e as características do ambiente por meio dos seus elementos originais, por experiência direta e por elementos visuais, sendo assim instrumento fundamental de programas de educação ambiental (PÁDUA; TABANEZ, 1997). Com isto, as trilhas permitem a transformação do meio natural em verdadeiras 
salas de aula e laboratórios vivos, constituindo uma valiosa ferramenta pedagógica ao nosso alcance.

Desenvolvendo estas atividades práticas com nossos alunos, estamos contribuindo para a Educação Ambiental, que segundo Dias (2004), tem a finalidade de promover a compreensão da existência e da importância da interdependência econômica, social, política e ecológica, induzindo novas formas de conduta nos indivíduos e na sociedade, a respeito do meio ambiente.

O principal objetivo deste estudo é através da Educação Ambiental, realizar uma trilha de interpretação, investigando o modo pelo qual os sujeitos surdos percebem o ambiente, utilizando os seus sentidos (olfato, tato, visão e paladar). Também, como objetivos específicos, identificar elementos do ambiente natural da trilha utilizando os sentidos; caracterizar o ambiente da trilha através de desenhos; comparar aspectos relacionados ao esperado e ao vivenciado na trilha; analisar a necessidade de atividades práticas diferenciadas para alunos surdos; analisar as relações de percepção existentes entre os alunos e os elementos da natureza.

\section{METODOLOGIA}

O grupo de estudo que participará da trilha consiste em 10 alunos surdos da 6a série do Ensino Fundamental da Escola Estadual Especial Keli Meise Machado, localizada no município de Novo Hamburgo, Rio Grande do Sul.

Para o desenvolvimento desta atividade foi utilizada a Trilha do Lago (Figura 1) localizada no campus da Universidade do Vale do Rio dos Sinos - Unisinos (Longitude 51 ${ }^{\circ} 9^{\prime} 20.03^{\prime \prime} \mathrm{W}$ e Latitude 29.7922). Esta trilha possui um percurso de 1.848 metros e está dividida em cinco trechos, onde podem ser observados diferentes aspectos ambientais, tais como, a geomorfologia da área, a vegetação, os vestígios animais, a ocorrência de fauna, além da ação antrópica sobre o meio ambiente.

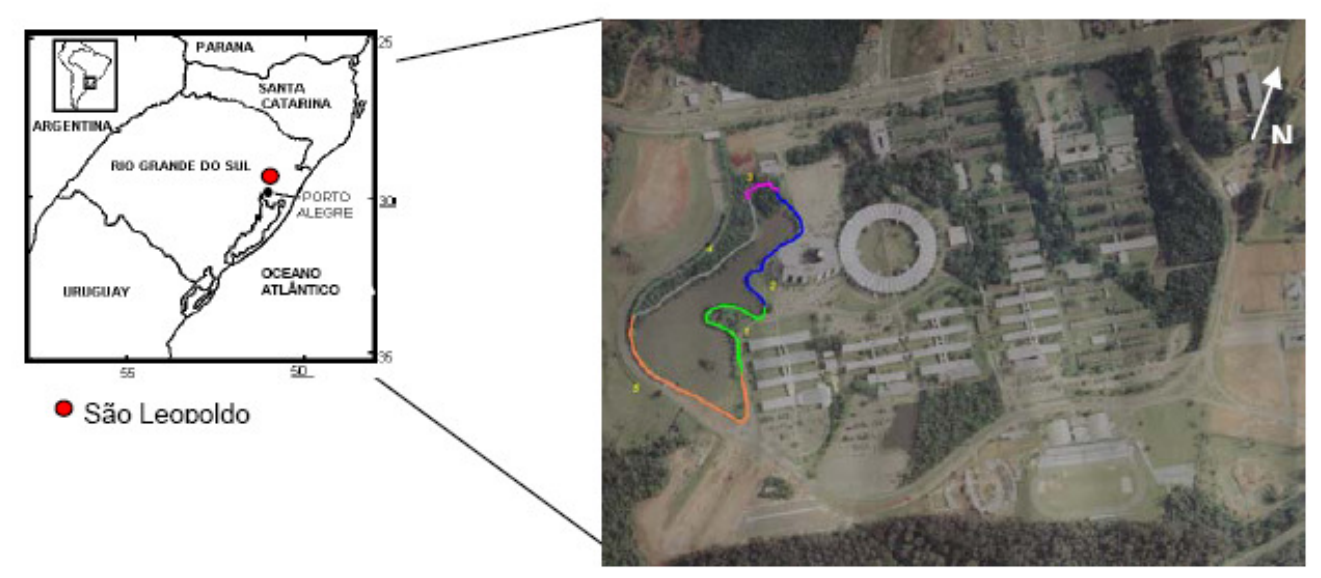

Figura 1 - Localização do campus da Universidade do Vale do Rio dos Sinos. Fonte: Google Earth (2011).

Nota: As linhas coloridas referem-se aos diferentes trechos ocorrentes na trilha do Lago, local onde ocorreu a trilha com os alunos. 
As atividades de interpretação ambiental foram elaboradas após a caracterização da área e da trilha, como também a caracterização dos alunos participantes da trilha, seu processo de aprendizagem, suas habilidades e competências. Após as observações foram criadas estações (pontos de parada e observação na trilha), para as quais foram confeccionados cartazes ilustrativos para auxiliar na compreensão dos seus aspectos. As estações receberam nomes de acordo com a principal característica a ser trabalhada. Durante a trilha, todas as explicações e interações feitas com os alunos surdos foram traduzidas para a Língua de Sinais por meio de um intérprete, com a finalidade de haver uma perfeita comunicação e compreensão entre os guias ouvintes e alunos surdos.

Antes do início de cada trilha o grupo foi dividido em duplas, para posterior atividade.

Estação 1 - Baleia: tem por objetivo mostrar aspectos ecológicos deste animal, bem como sua relação com o ambiente. Nesta estação tem o esqueleto montado de uma baleia. Foi explicado para o grupo a história desta baleia, o processo de montagem do seu esqueleto e algumas características morfológicas e fisiológicas deste mamífero. Os alunos puderam tocar nos ossos do animal.

Estação 2 - Canteiro de Boldo: no canteiro de boldo do Chile, os alunos puderam tocar e cheirar as folhas do chá. Foi explicado aos alunos qual finalidade desta planta.

Estação 3 - Folhas e caules: nesta área da trilha, há diferentes espécies de árvores e arbustos. Nela, os alunos puderam perceber as diferenças entre folhas e caules (texturas, tamanhos, nervuras das folhas, cores). Os alunos puderam tocar nas diferentes folhas e caules, a fim de perceber estas diferenças.

Estação 4 - Lago: em várias partes da trilha pode-se ver o lago. Porém nesta estação, o grupo pode se aproximar do lago e visualizar cágados e peixes. Foi explicado como o lago foi construído e quais animais que o habitam. O grupo teve a oportunidade de alimentar os peixes com ração.

Estação 5 - Embaúba (Cecropia pachystachya TREC.): a árvore Embaúba cresce em diversos pontos da trilha. Nesta estação foi explicado o mutualismo existente entre a árvore e as formigas.

Estação 6 - Cupinzeiro: neste momento da trilha os alunos já estão em um local de mata mais fechada, na qual exibe um cupinzeiro inativo. Foi questionado ao grupo, qual animal habita aquele local, já que há indícios de aranhas, como por exemplo teias antigas.

Estação 7 - Pinnus: nesta área da mata existem muitos exemplares de Pinnus. Foi solicitado que os alunos observassem o chão da mata. Foi questionado o porquê do solo ter pouca vegetação e qual a relação existente com a árvore. Também foi explicado a problemática das espécies exóticas.

Estação 8 - Toca do tatu: na trilha, há um local onde existe uma toca de tatu. Foi explicado como o animal faz a toca e para qual finalidade a utiliza. Também foi questionado quais alunos já viram um tatu na natureza ou no zoológico.

Estação 9 - Câmera fotográfica: neste momento da trilha, os alunos novamente foram até a estação Folhas e caules, onde foi aplicada uma atividade em duplas que foi desenvolvida pelo educador ambiental Cornell (1997) e adaptada para este estudo. Tal atividade tem o objetivo de chamar a atenção dos alunos a perceberem o ambiente natural. Um participante assume 0 papel do fotógrafo e o outro representa a máquina fotográfica. O fotógrafo guia a câmera, que está de olhos fechados, à procura de imagens bonitas e interessantes. Ao ver algo que lhe interessa, o fotógrafo aponta a objetiva (os olhos) da câmera naquela direção e enquadra o objeto que quer fotografar. Em seguida é dado um sinal, para abrir a objetiva (abrir os olhos) e tirar a 
foto, usando uma moldura vazada para focar e não deixar que a "câmera" se abstraia com o restante do ambiente. Os fotógrafos devem ser incentivados a ser criativos ao escolher e enquadrar os objetos. Os fotógrafos tiveram de 5 minutos para fotografar e rapidamente após a fotografia, esta será revelada pela câmera, através de um imediato desenho. Depois as duplas trocarão de função.

Ao término da trilha os alunos se reuniram no espaço "Tenda da Vida", próximo ao local de estudo para realizarem algumas atividades:

a) retomada das estações da trilha por meio de cartazes ilustrativos;

b) rápida conversa sobre o que foi visto na trilha: o que os alunos esperavam da trilha, o que foi mais significativo, algo que nunca tinham presenciado antes;

c) questionário: todos os alunos responderam a um questionário sobre a trilha. As perguntas foram traduzidas para a Língua de Sinais e a professora intérprete auxiliou os alunos que não são totalmente alfabetizados a formularem suas respostas na Língua Portuguesa;

d) após, os alunos sentaram ao lado do colega que realizaram a atividade da Câmera Fotográfica. As duplas fizeram uma reflexão sobre as revelações das fotos. Após foi comparado se a foto revelada pela "câmera" realmente foi o esperado pelo observador no momento em que a foto foi tirada.

Com isto, os desenhos e os questionários foram analisados para posterior tabulação dos resultados.

\section{RESULTADOS E DISCUSSÃO}

A partir da análise dos questionários, alguns gráficos foram feitos para melhor observação e compreensão dos resultados. No primeiro gráfico (Figura 2), observou-se a percepção dos alunos quanto a presença de animais nas diferentes estações da trilha, referente a pergunta um do questionário. Percebe-se que $100 \%$ dos alunos observaram animais que realmente encontravamse na trilha, como por exemplo pato e aves. Todos os alunos também responderam no questionário terem visto o animal "Baleia", apesar de somente seu esqueleto ter sido apresentado ao grupo. Poucos alunos (10\%) observaram animais que não estavam presentes nas estações, como o tatu e a aranha. Pois, na verdade, foram encontrados somente vestígios destes animais como teias e tocas, mas não foram feitos avistamentos reais. 


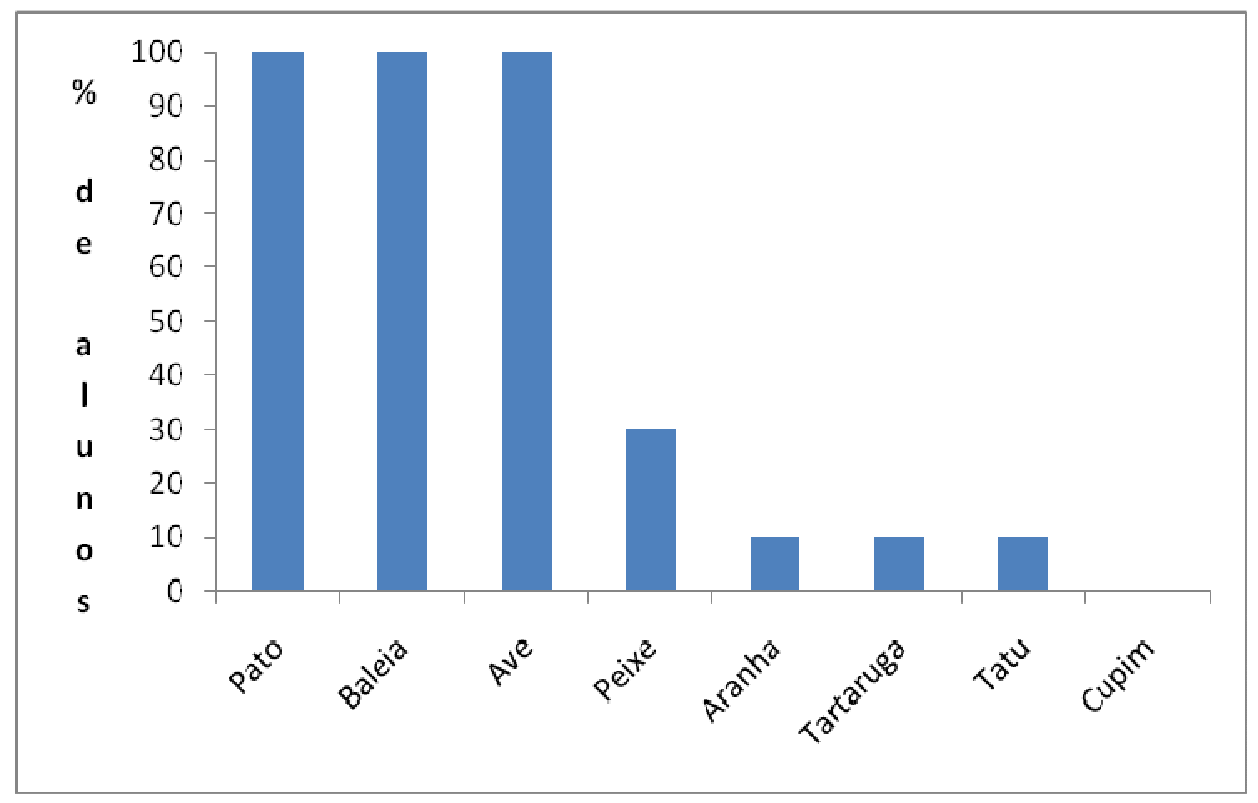

Figura 2 - Animais observados pelos alunos. Fonte: Elaborado pela autora.

A figura 3 mostra os resultados da pergunta quatro do questionário, a qual indagava sobre a observação dos alunos quanto a presença de vestígios animais nas estações da trilha. De acordo com o gráfico (Figura 3), foram observados cinco vestígios animais pelos alunos. $90 \%$ do grupo observaram a toca do tatu, $80 \%$ a toca do preá e $70 \%$ observaram a teia da aranha. A toca do preá não fazia parte das estações da trilha, porém em um ponto da trilha, perto da Estação Folhas e caules as tocas foram encontradas. A guia da trilha fez uma breve explicação sobre o animal e como este faz sua toca. Os outros vestígios foram observados por poucos alunos ( $20 \%$ as fezes de pato e $10 \%$ o cupinzeiro). Como muitos alunos já haviam observado a teia da aranha como vestígio no cupinzeiro, este pode ter sido um dos fatores pelo qual os alunos não relataram o próprio cupinzeiro como vestígio para o cupim. Estes dados revelam que o grupo de alunos esteve atento aos vestígios, compreendendo seus significados e suas relações com o meio ambiente. Também nos mostra que a maioria dos alunos lembrou das observações quando responderam o questionário. 
Monografias Ambientais

REMOANFSM

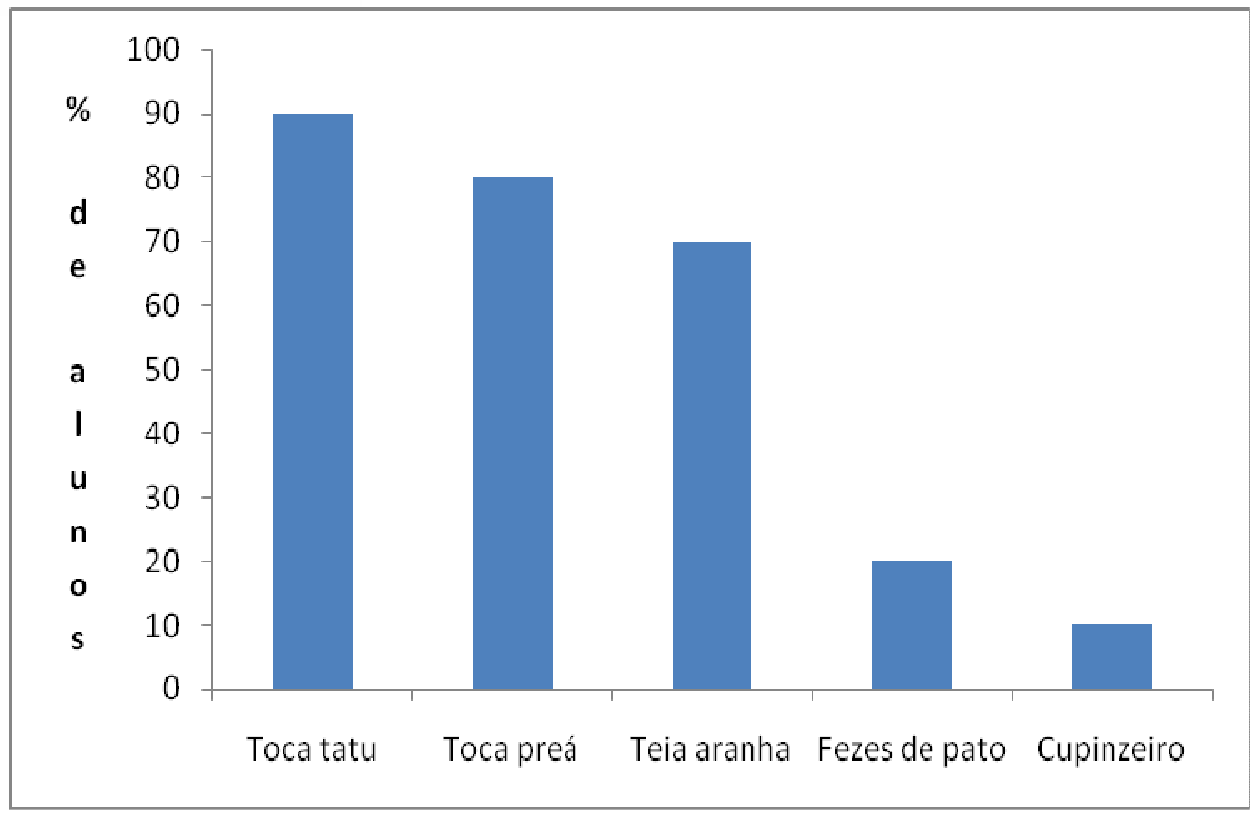

Figura 3 - Vestígios animais observados pelos alunos.

Fonte: Elaborado pela autora.

No questionário foi perguntada a necessidade ou não da audição para perceber elementos da trilha. Todos os alunos negaram esta necessidade. Também foi questionado em quais Estações os alunos utilizaram o olfato e o tato. Todos os alunos fizeram relações com as Estações que realmente tinham elementos que estabeleciam ligações com estes órgãos do sentido, como por exemplo a Estação Boldo e a Estação Folhas e caules.

A questão sete deste questionário solicitava que os alunos representassem em forma de desenho o que mais chamou a atenção durante a trilha. De acordo com as observações dos desenhos, nota-se que as representações de alguns alunos possuem mais elementos (figuras $4 \mathrm{e}$ 5). Isto deve-se a maior vivência e visão de mundo que estes alunos possuem. Há uma estreita ligação entre o ambiente natural e a visão do mundo, de acordo com Tuan (1980, p. 90): "a visão do mundo, se não é derivado de uma cultura estranha, necessariamente é construída dos elementos conspícuos do ambiente social e físico de um povo". Isto também está relacionado a vida social destes sujeitos, pois possuem maior poder aquisitivo/econômico, podendo conhecer e adquirir mais bens do que alguns dos outros alunos. 


\section{Monografias Ambientais}

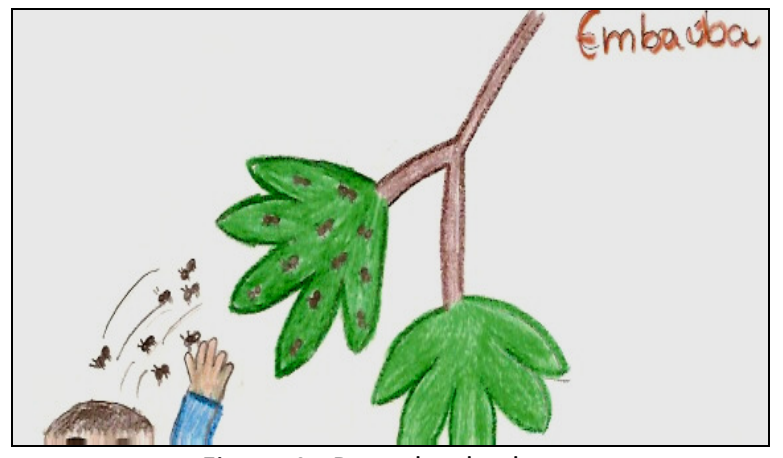

Figura 4 - Desenho de aluno.

Fonte: Desenho registrado por aluno.

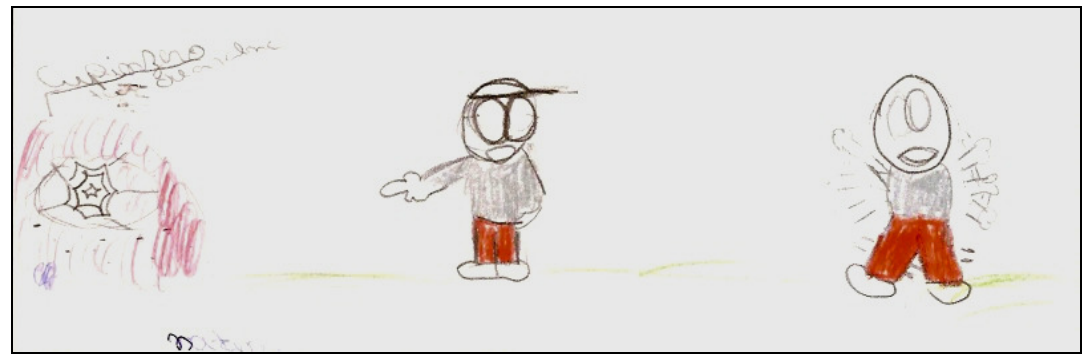

Figura 5 - Desenho de aluno.

Fonte: Desenho registrado por aluno.

Porém nos desenhos dos restantes dos alunos são percebidas mais representações reais daquilo que estes observaram na trilha (figuras 6 e 7). Não há desenhos de objetos e elementos que não foram realmente observados. Podemos sugerir que estes desenhos foram mais fiéis aos elementos da trilha.

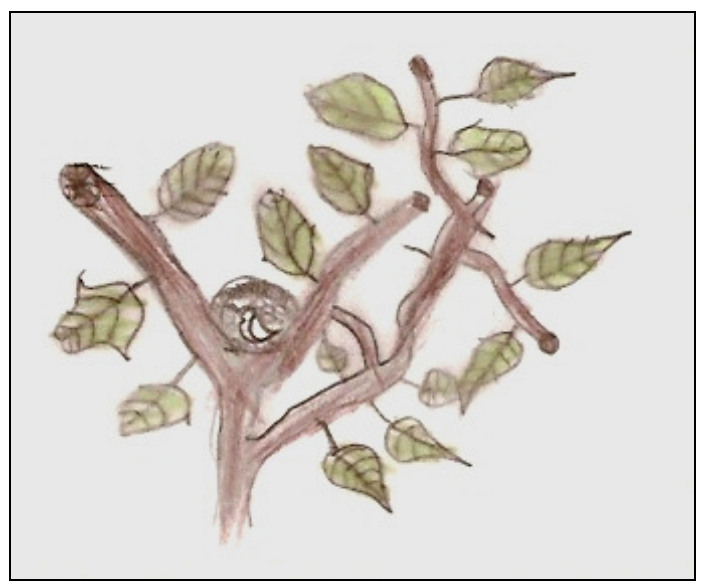

Figura 6 - Desenho de aluno.

Fonte: Desenho registrado por aluno. 


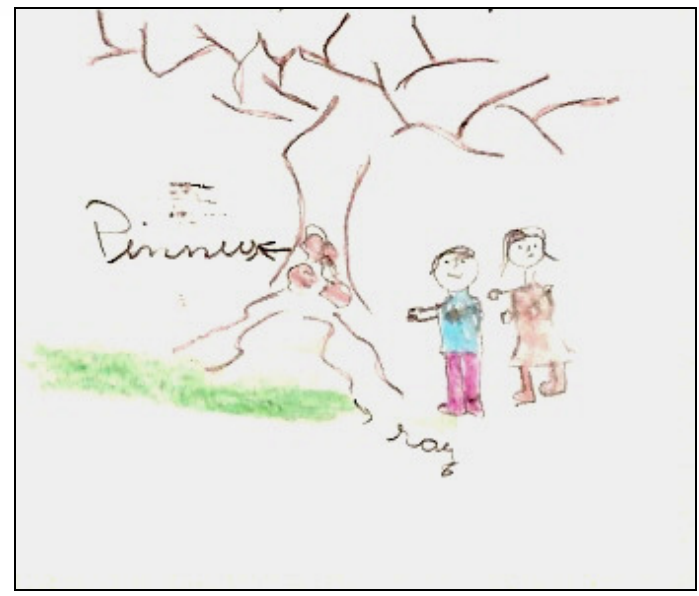

Figura 7 - Desenho de aluno. Fonte: Desenho registrado por aluno.

$\mathrm{Na}$ atividade da câmera fotográfica realizada com o grupo de alunos, nota-se que estes preferiram "fotografar" mais árvores, flores e caules. As revelações (desenhos) foram pouco significativas, com traços pouco expressivos, dificultando a identificação do que foi "fotografado". Nota-se que houve pouca retenção da imagem a ser visualizada para posterior representação gráfica em forma de desenho. Posteriormente, quando os alunos foram questionados o quanto as revelações foram fiéis às fotografias, todos os alunos concordaram com os resultados e acharam satisfatórias as fotografias. Portanto, podemos perceber que mesmo sem nenhuma interação com a dupla, somente com a intuição e a sensibilidade, todos conseguiram captar as imagens exatas que os colegas estavam planejando fotografar. Pois, em nenhum momento durante a atividade as duplas puderam conversar, só utilizaram o tato para guiar o colega da respectiva dupla.

Parte do resultado pouco satisfatório desta atividade, deve-se ao fato da atividade ter sido realizada ao final da trilha, onde alguns alunos já estavam cansados da caminhada, sem paciência de realizar a atividade, a qual necessita de muita atenção e calma. É importante ressaltar que todos os alunos gostaram muito de realizar a atividade, porém seu maior objetivo não foi alcançado: o de perceber um elemento da natureza, já percebido pelo colega e representá-lo com detalhes e não de maneira superficial como foi realizado. Também poderia ter sido estipulado um tempo maior para a atividade, a fim das duplas terem mais tempo de investigar o local e descobrir elementos para fotografar. $O$ tempo de captura da imagem também poderia ter sido maior. Outro fato relevante é sobre a interferência sonora durante a atividade, a qual os surdos são beneficiados, uma vez que a audição neste momento não se fazia necessária.

De acordo com Sacks (1998), testes visuais-espaciais aplicados em crianças chinesas surdas e ouvintes revelaram que as crianças surdas usuárias da língua de sinais conseguem reproduzir graficamente caracteres chineses (apresentados em pontos de luz em movimento) com muito mais eficiência do que as crianças ouvintes. Parece que as crianças surdas conseguem "decompor" esses pseudocaracteres, fazer uma análise espacial muito complexa, permitindo-lhes reproduzir graficamente com muito mais propriedade do que os ouvintes. Esta comparação não pode ser feita com a atividade da câmera fotográfica no estudo em questão, mas há relatos na literatura desta habilidade dos surdos em reter mais imagens do que ouvintes.

Após o término das trilhas, fez-se questionamentos aos alunos quanto a trilha: o que mais gostaram, se já conheciam o local da atividade, o que mais acharam interessante, se na atividade 
da câmera fotográfica as fotos reveladas foram o que as "objetivas" focaram. Notou-se muita satisfação por parte dos alunos. Todos se mostraram muito felizes e entusiasmados com a trilha e com as atividades realizadas, relatando terem aprendido muito com as mesmas. Foi observado que durante a trilha houve muito mais interação entre a monitora com um grupo particular de alunos, os quais fizeram muitos questionamentos, relatos e observações. A aluna Ana ${ }^{1}$ comentou: "Já tinha feito outras trilhas, mas nunca tinha reparado tantas coisas legais na natureza!". O restante do grupo também observou elementos que a monitora não comentou, mas fizeram poucas perguntas e poucas interferências. Muitos ficaram encantados ao observarem o casal de pássaros João de barro construir o ninho, o aluno Anderson" admirado comentou: "Como a ave sabe fazer sozinha uma casa tão perfeita, que não cai!". Apesar de toda trilha ter sido traduzida para a Língua de Sinais, a pouca vivência da monitora com sujeitos surdos pode ter influenciado neste dado. Também os próprios surdos quando sabem que vão visitar um local frequentado por mais ouvintes, acabam se privando e se constrangendo em fazer questionamentos e relatos. Isto sugere a necessidade de profissionais da área da surdez em locais públicos, possibilitando o atendimento destes sujeitos com necessidades especiais, viabilizando uma perfeita comunicação.

Analisando todos os resultados, estes vão ao encontro dos diversos autores (NEVILLE; BELLUGI, 1978; SACKS, 1998) que afirmam que a perda da audição pode levar a uma compensação pela visão, adquirindo certa intensificação da sensibilidade visual passando a apresentar uma orientação mais visual do mundo, como afirma Wright (1969).

Segundo Cornell (1997) a mente se torna tranquila e mais receptiva, após um contato direto com a natureza. Afirma que a experiência direta possibilita alcançar e sentir outras realidades, pois desperta o sentido de admiração e também possibilita conhecer o mundo que nos rodeia com maior amplitude. Enfim, com este trabalho reforçamos a importância e a necessidade de atividades práticas nas salas de aula com alunos surdos que os levem a estar em contato direto com o meio ambiente, possibilitando despertar questões e valores ligados a natureza. Pois, somente com esta interação é possível sair da limitação do "visual" e conseguir sentir, cheirar, tocar e experimentar a natureza.

Estas constatações vão de encontro com Quadros (2003, p. 93, grifo do autor):

As experiências visuais são as que perpassam a visão. O que é importante é ver, estabelecer as relações de olhar (que começam na relação que os pais surdos estabelecem com os seus bebês), usar a direção do olhar para marcar as relações gramaticais, ou seja, as relações entre as partes que formam o discurso. $O$ visual é o que importa. A experiência visual desde o ponto de vista físico (os encontros, as festas, as estórias, as casas, os equipamentos...) até o ponto de vista mental (a língua, os pensamentos, as ideias...). Como consequência é possível dizer que a cultura é visual. As produções linguísticas, artísticas, científicas e as relações sociais são.

Com isto, concordamos com Minini (2000) quando conceitua Educação Ambiental como um processo que propicia às pessoas uma compreensão crítica e global do ambiente, a fim de despertar valores e desenvolver atitudes que lhes permitam posicionar-se de forma consciente e participativa em relação a questões ligadas a conservação e utilização adequada dos recursos naturais, visando a melhoria da qualidade de vida. Realizando práticas de sensibilização e

\footnotetext{
${ }^{1}$ Nome fictício da aluna, para preservar a identidade.

${ }^{2}$ Nome fictício do aluno, para preservar a identidade.
} 
percepção ambiental, como a descrita neste trabalho, estaremos desenvolvendo com nossos alunos uma verdadeira Educação Ambiental.

\section{CONCLUSÃO}

A partir das situações vivenciadas pode-se observar que o sujeito surdo utiliza todos os seus sentidos para perceber o ambiente de forma integral. Pela falta da audição, são mais sensíveis ao visual e a expressão das pessoas, conseguindo estabelecer relações mais perfeitas entre si, com outras pessoas, e mesmo com o meio ambiente. A percepção do som está relacionada a presença da vibração que este produz em seu próprio corpo, como por exemplo a batida grave de uma música alta é facilmente percebida pelo surdo, pois o seu próprio corpo vibra. Durante a trilha, podemos notar que os elementos da natureza que produzem sons também foram facilmente percebidos pelos alunos, através de seus movimentos e relações com animais.

Também podemos observar que os elementos que produzem som, porém não vibram nem são sentidos no corpo do sujeito, são relacionados ao som pelo movimento ou por algum conhecimento prévio que a pessoa possua. $O$ fato de não identificar alguns sons, não interfere significativamente na percepção do ambiente, pois, observando os desenhos feitos pelos alunos após a trilha percebemos que todos usaram traços e elementos bem significativos da trilha que chamaram sua atenção.

Refletindo sobre os resultados do presente trabalho, percebemos que os alunos não conseguem se manter atentos e interessados nas atividades por longo período de tempo. Para uma próxima oportunidade de práticas de percepção ambiental, seria interessante realizar a atividade da "câmera fotográfica" isoladamente, sem antes fazer uma trilha, pois assim os alunos estariam mais dispostos e os resultados poderiam ser mais satisfatórios.

De forma particular, neste trabalho foram somadas duas paixões profissionais, as quais permeiam minhas angústias e práticas: a educação de surdos e a Educação Ambiental. Creio que realizando atividades práticas de sensibilização ambiental, estaremos despertando o respeito a natureza, valorizando-a e participando de uma tomada de consciência quanto a mudança de paradigmas e atitudes. Realizar estas práticas com os alunos surdos significa redescobrir a natureza, através de seus olhares, percepções e mãos.

\section{REFERÊNCIAS}

BRASIL. Secretaria de Educação Fundamental. Parâmetros curriculares nacionais: terceiro e quarto ciclos do ensino fundamental: ciências naturais. Brasília, DF: MEC/SEF, 1998.

CORNELL, J. A alegria de aprender com a natureza: atividades na natureza para todas as idades. São Paulo: SENAC, 1997.

DIAS, G. F. Educação ambiental: princípios e práticas. 9. ed. São Paulo: Gaia, 2004.

GOOGLE Earth. São Leopoldo: Unisinos. 2011. Disponível em: <http://earth.google.com/intl/pt/>. Acesso em: 20 jul. 2011. 
LEFF, E. Pensar a complexidade ambiental. In: LEFF, E. (Org.). A complexidade ambiental. São Paulo: Cortez, 2003. p. 15-64.

LOPES, M. C. A natureza educável do surdo: a normalização surda no espaço da escola de surdos. In: THOMA, A. S.; LOPES, M. C. (Org.). A invenção da surdez: cultura, alteridades, identidades e diferença no campo da educação. Santa Cruz do Sul: EDUNISC, 2004. p. 128-142.

MININI, N. A formação dos professores em Educação Ambiental. In: TEXTOS sobre Capacitação em Educação Ambiental: oficina panorama da Educação Ambiental. Brasília, DF: MEC/SEF/DPEF, 2000. p. 15-22.

NEVILLE, H. J.; BELLUGI, U. Patterns of cerebral specialization in congenially deaf adults: a preliminary report. In: SPILE, P. (Ed.). Understanding language through Sign Language research. New York: Academic Press, 1978. p. 230-257.

PÁDUA, S. M.; TABANEZ, M. F. Educação Ambiental: caminhos trilhados no Brasil. Brasília, DF: Ipê, 1997.

QUADROS, R. M.. Situando as diferenças implicadas na educação de surdos: inclusão/exclusão. Ponto de vista, Florianópolis, n. 5, p. 81-111, 2003. Disponível em: <http://www.perspectiva.ufsc.br/pontodevista_05/05_quadros.pdf>. Acesso em: 16 nov. 2011.

QUADROS, R. M. O tradutor e intérprete de Língua de Sinais Brasileira. 2. ed. Brasília, DF: MEC, 2004.

QUADROS, R. M.; KARNOPP, L. B. Língua de Sinais Brasileira: estudos linguísticos. Porto Alegre: Artmed, 2004.

SACKS, O. W. Vendo vozes: uma viagem ao mundo dos surdos. São Paulo: Companhia das Letras, 1998.

SAUL, P. F. A.; LEAL, J. C.; FENSTERSEIFER, C. Trilhas de interpretação ambiental. In: NOWATZKI, C. H. (Org.). Educação Ambiental: teoria e prática. São Leopoldo: Editora Unisinos, 2002. p. 107114.

SAVIANI, D. Saber escolar, currículo e didática. Campinas: Autores Associados, 2000.

SKLIAR, C. Os estudos surdos em educação: problematizando a normalidade. In: SKLIAR, C. (Org.). A surdez: um olhar sobre a diferença. Porto Alegre: Mediação, 1998. p. 7-32.

TUAN, Yi-fu. Topofilia: um estudo da percepção, atitudes e valores do meio ambiente. São Paulo: DIFEL, 1980.

WRIGHT, D. Deafness. New York: Stein and Day, 1969.

WRIGLEY, O. The politics of deafness. Washington: Gallaudet University Press, 1996. 